\title{
Use of Local Dynamic Electricity Prices for Indirect Control of DER Power Units
}

\author{
Nørgård, Per Bromand; Isleifsson, Fridrik Rafn
}

Published in:

Proceedings of CIRED 2013

Link to article, DOI:

10.1049/cp.2013.0642

Publication date:

2013

Document Version

Publisher's PDF, also known as Version of record

Link back to DTU Orbit

Citation (APA):

Nørgård, P. B., \& Isleifsson, F. R. (2013). Use of Local Dynamic Electricity Prices for Indirect Control of DER Power Units. In Proceedings of CIRED 2013 [0267] IEEE. https://doi.org/10.1049/cp.2013.0642

\section{General rights}

Copyright and moral rights for the publications made accessible in the public portal are retained by the authors and/or other copyright owners and it is a condition of accessing publications that users recognise and abide by the legal requirements associated with these rights.

- Users may download and print one copy of any publication from the public portal for the purpose of private study or research.

- You may not further distribute the material or use it for any profit-making activity or commercial gain

- You may freely distribute the URL identifying the publication in the public portal

If you believe that this document breaches copyright please contact us providing details, and we will remove access to the work immediately and investigate your claim 


\section{USE OF LOCAL DYNAMIC ELECTRICITY PRICES FOR INDIRECT CONTROL OF DER POWER UNITS}

\author{
Per NØRGAARD \\ DTU - Denmark \\ pern@elektro.dtu.dk
}

\author{
Fridrik Rafn ISLEIFSSON \\ DTU - Denmark \\ fris@elektro.dtu.dk
}

\begin{abstract}
The regulation capability that may be provided by the individual small-scale distributed energy resources (DER power units) may be insignificant. However, the aggregated response from a large number of DER power units can be significant and thereby provide valuable system services to the power system. A challenge is to find a cheap, simple and robust way to requests the proper power regulation by the DER power units. The use of broadcasted, dynamic power prices and volunteer responses is one option.

The paper presents a proposal for and an illustration of advanced generation of local, dynamic electricity prices for indirect control of active power. The local, dynamic electricity prices are realised as dynamic adjustments of the quasi-stationary global power price. The aims of the dynamic price adjustments are to prevent overloading of the grid, to reduce the grid power losses and to regulate the grid voltage. The algorithms generating the local prices are dynamically adjusted according to the actual realised responses to the dynamic prices.

Results are presented from an adapted version of the control principle implemented and tested in DTUs experimental research power system, SYSLAB, including wind power, solar power, flexible load and electrical storage. The local power price generation is based on the actual Nord Pool DK2 Spot prices on hourly basis as the quasi-stationary global electricity price, and the local SYSLAB's power exchange with the national grid as basis for the dynamic price adjustment.
\end{abstract}

\section{INTRODUCTION}

Negative SPOT prices (hourly power prices announced one day ahead) were introduced at the Nordic power market, Nord Pool, few years ago as a consequence of the increasing wind power penetration and the related temporally excess power generation and power congestions in the power transmission system - see the example from December 2012 in Figure 1. These dynamic, and even negative, power prices are one mean to control the power balance between supply and demand, based on voluntary responses and appropriate power markets.

\section{THE CONCEPT}

This dynamic nodal pricing concept, with local, dynamic power prices and voluntary responses from active supply (generation) and demand (consumption) distributed energy resource (DER) power units within a defined power price area, can be further developed to address faster and more local power congestions in real time, also in the lower voltage part of the power grid.

A new, simplified power market and communication is required, if the small-scale DER units should also be activated. The responses from the individual small-scale DER units may be insignificant, but the aggregated response from a huge number of small-scale DER units may be significant. The responses from these small-scale DER units must therefore be very simple and fully automated. One option is broadcast communication of the power price in combination with voluntary, autonomous power responses.

However, the use of local, dynamic electricity prices for intelligent, indirect control of DER units requires: 1) an accounting scheme designed for power trading based on dynamic electricity prices; 2) identification of appropriate local power price areas; 3 ) access to detailed, online information of the status of the grid; 4) generation of local, dynamic electricity prices reflecting the local power system needs and with sufficient variations in the electricity prices to form the basis for business cases, resulting in the required response; 5) on-line communication of the dynamic electricity prices to the DER units; and 6) DER units designed to respond to dynamic electricity prices.

For the definition of price areas, it would be natural to base that on the power grids connected to the power substations at a given voltage level. On the one hand, the price areas must be small enough to address the actual grid congestions. But, on the other hand, the number of price areas should also be manageable. Any power grid congestions within a price area must be met by other

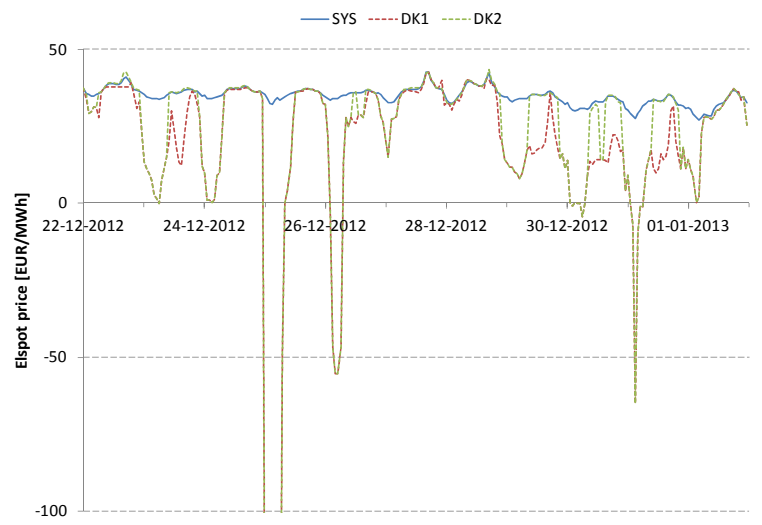

Figure 1: Example of negative SPOT-prices in the Nordic power market, Nord Pool, for price area DK2 (West Denmark) in December 2012, mainly due to the combination of high wind and public holidays. 
Paper 0267

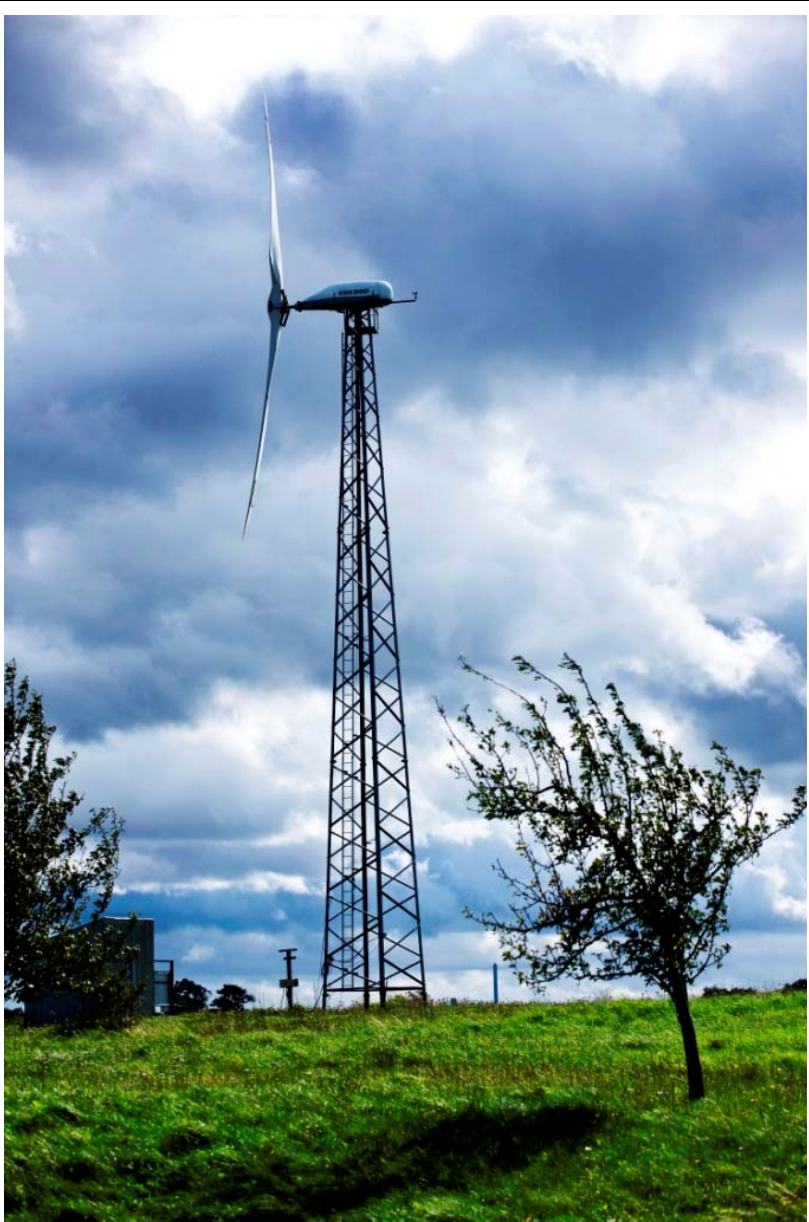

Figure 2: The $11 \mathrm{~kW}$ Gaia wind turbine used in the experiment.

(local and autonomous) control means.

Adequate on-line power information, as basis for the local price generation, is typically already externally available from the power sub-stations. The variations of the local power price must be based on experiences, and should be implemented using an adaptive learning algorithm. With just 10 independent responding actors of similar power scale, the voluntary aggregated power regulating response to a given change in the power price will be sufficient predictable.

The price dynamics should reflect the dynamics in the power system's needs for regulation. Power systems with local wind and / or solar power generation may require regulations within minutes. The dynamic power prices and thereby the regulation - may include prices for both active power and reactive power, providing improved options to regulate both grid load and grid voltage.

With price areas defined by the grids at the lowest voltage side of selected sub-stations, power line communication - with repeaters bypassing the transformers at lower voltage levels - could be used to communicate the local, dynamic power prices from the substations to the local actors.

Modern, electronically power meters can typically collect the local energy information with resolutions down to 5 minutes intervals. The shorter price intervals, the more energy numbers must be combined with individual power prices to calculate the total amount for a period for each costumer. Power grids can typically be slightly

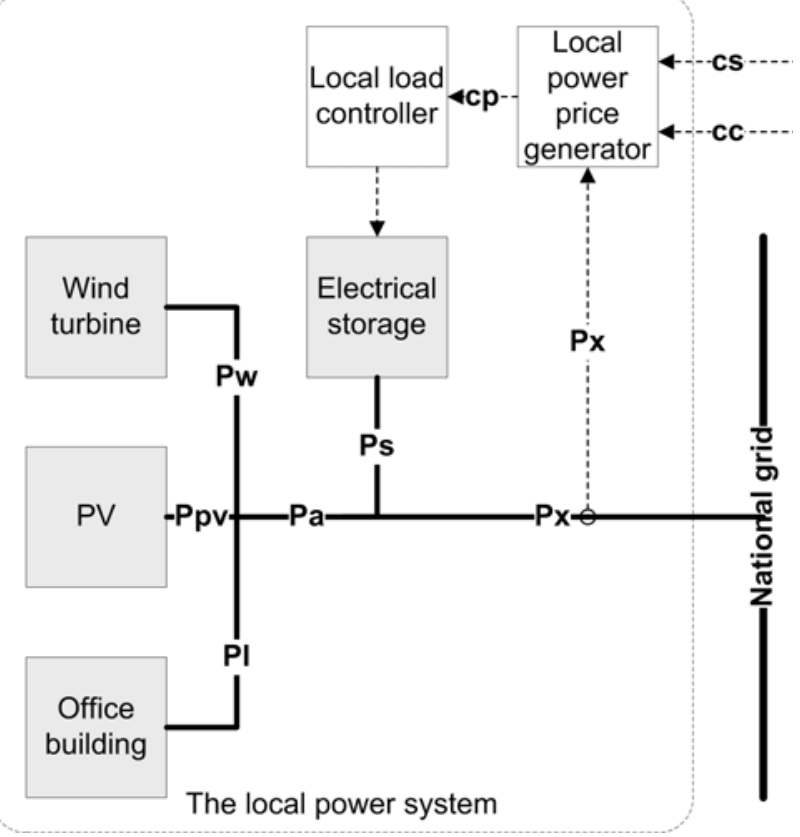

Figure 3: Illustration of the experimental setup in SYSLAB. A local, dynamic power price, $\mathrm{cp}$, is generated based on the global SPOT price, $c_{s}$, a fixed local price compensation, $c_{c}$, and the power exchange, $\mathrm{P}_{\mathrm{x}}$, between the local power system (SYSLAB) and the global power system (the national grid).

overloaded in few minutes without problems.

The combination of price and energy may be calculated and summarised locally by the power meter at the costumer, reducing the amount of information to be collected from the individual costumers. However, at least in Denmark, this requires fundamental changes in the regulation and accounting schemes.

\section{EXPERIMENTAL ILLUSTRATION OF THE CONCEPT}

The local, dynamic power price concept is illustrated at the experimental small-scale power system research facility, SYSLAB, at The Technical University of Denmark (DTU).

At SYSLAB, a local power system with wind power, $\mathrm{P}_{\mathrm{w}}$ $(10 \mathrm{~kW})$, solar power, $\mathrm{P}_{\mathrm{pv}}(7 \mathrm{~kW})$, office building, $\mathrm{P}_{1}$ (max $10 \mathrm{~kW}$, mainly for space heating) and electrical storage, $\mathrm{P}_{\mathrm{s}}(15 \mathrm{~kW} / 150 \mathrm{kWh})$ is connected to the national power system in a single connection point, $\mathrm{P}_{\mathrm{x}}-$ see Figure 3.

The sum of the wind power, the solar power and the office building power is denoted the aggregated power:

$$
P_{a}=P_{w}+P_{p v}+P_{l}
$$

The power exchange, $P_{x}$, between the local power system and the national grid is given by the sum of the aggregated power and the storage power:

$$
P_{x}=P_{a}+P_{s}
$$

To illustrate the control, $\mathrm{P}_{\mathrm{x}}$ is assumed limited by the power capacity of the cable, $P_{x}{ }^{\max }=5 \mathrm{~kW}$.

A local power price, $c_{p}$, is generated based on the global SPOT price on hour basis, $\mathrm{c}_{\mathrm{s}}$, a local price compensation, $c_{c}$, and the power exchange, $P_{x}$ :

where

$$
c_{p}=c_{s}+c_{c}+c_{x}
$$




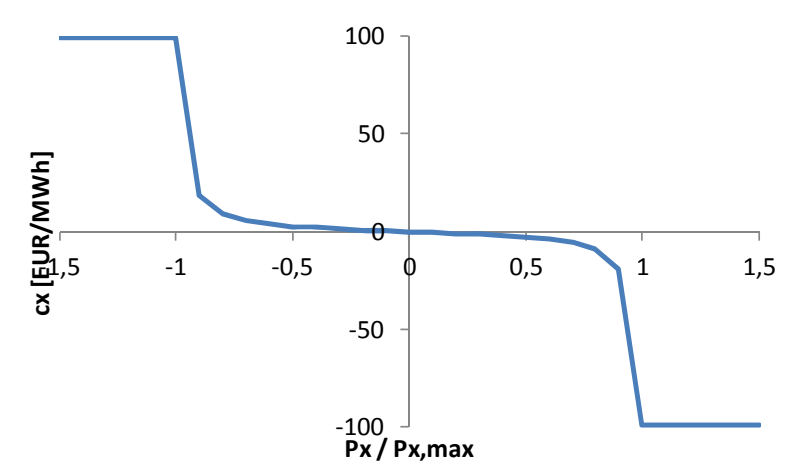

Figure 4: Illustration of the local, dynamic price adjustment, $c_{x}$, as function of the power exchange, $P_{x}$.

$$
c_{x}=f_{x}\left(P_{x}\right)
$$

is a function of $\mathrm{P}_{\mathrm{x}}$ as illustrated in Figure 4.

As long as the power exchange, $\mathrm{P}_{\mathrm{x}}$, is far from the limit, $\mathrm{P}_{\mathrm{x}}{ }^{\text {max }}$, the local, dynamic price adjustment, $\mathrm{C}_{\mathrm{x}}$, is insignificant. As $P_{x}$ get close to $\pm P_{x}^{\max } c_{x}$ becomes significant, motivating the local, active actors to adjust their power, if possible.

The local compensating price, $\mathrm{c}_{\mathrm{c}}$, can be used to level out any differences between the local prices for different areas.

In the illustrating example, only the storage power is controlled - see Figure 3:

$$
P_{s}=f_{s}\left(c_{d}\right)
$$

defined by dependency of the power exchange, $\mathrm{P}_{\mathrm{x}}$, in Figure 4 and the dead band for the storage unit, defined in Figure 6, and where

$$
c_{d}=c_{p}-c_{p}^{\text {exp }}
$$

is the difference between the local power price, $\mathrm{c}_{\mathrm{p}}$ and the expected local power price, $c_{p}{ }^{\exp }-$ in the illustrative example the same as the SPOT price, $\mathrm{c}_{\mathrm{s}}$. The local price compensation, $\mathrm{c}_{\mathrm{c}}$, is assumed to be 0 .

The experiment was done at a day with very stable SPOT price - see Figure 5.An example of the SPOT price, $c_{s}$, and the local power price adjustment, $\mathrm{c}_{\mathrm{x}}$, are illustrated in Figure 7.

In the illustrating example, the power productions from the wind and solar, and the power consumption from the office building fluctuates, and the aggregated power, $\mathrm{P}_{\mathrm{a}}$,

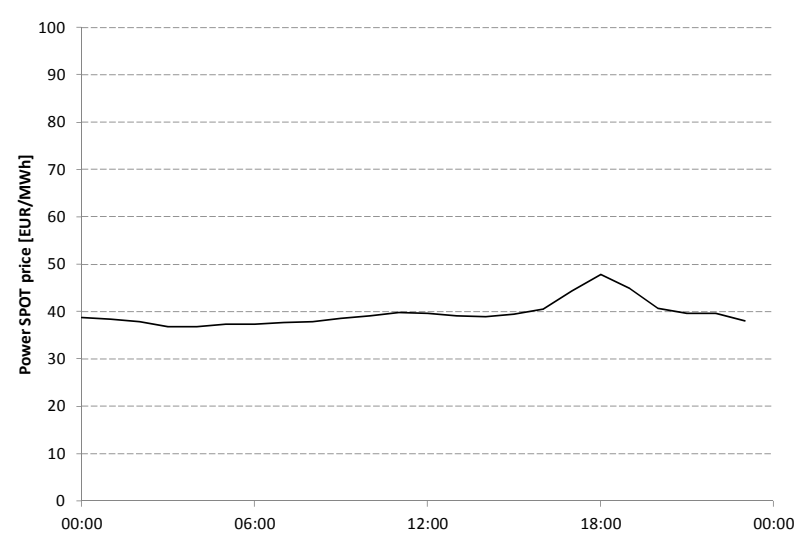

Figure 5: Example of the actual SPOT price, $\mathrm{c}_{\mathrm{s}}$, on hourly basis for the Nord Pool price area DK2 on 13 Jan 2012.

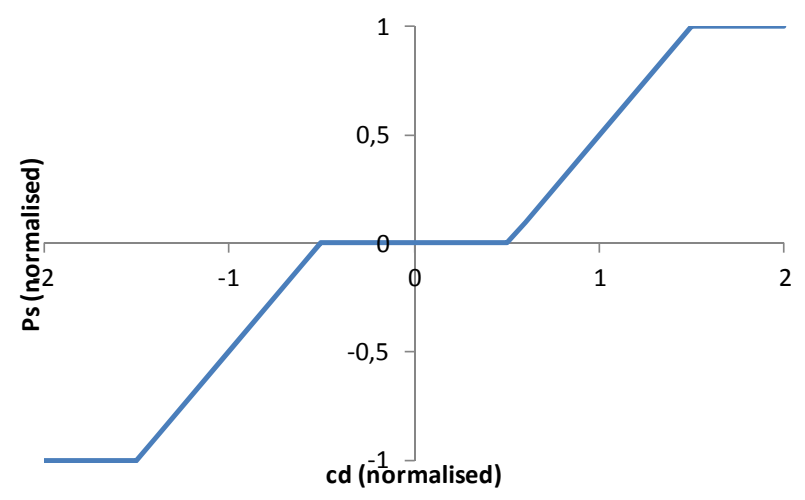

Figure 6: Illustration of the control of the storage power, Ps, as a function of the deviation, $c_{d}$, of the actual local power price, $c_{p}$, from the expected local price, $c_{p}{ }^{\exp }$.

shifts between positive (excess local power generation) and negative (deficit local power generation) - see Figure 8.

The resulting power exchange with the national grid, $\mathrm{P}_{\mathrm{x}}$, is used to generate a local adjusting power price, $C_{x}$, (see Figure 4). When $P_{x}$ is negative (corresponding to power import), $c_{x}$ becomes positive, and when $P_{x}$ is positive (corresponding to power export), $\mathrm{C}_{\mathrm{x}}$ becomes negative see Figure 9.

The resulting local power price, $\mathrm{c}_{\mathrm{p}}$, is then used as input to the control of the storage power, $\mathrm{P}_{\mathrm{s}}-$ see Figure 3 and Figure 6. A dead band is introduced to prevent that the storage unit is active when $c_{d}$ is close to 0 and the internal power losses in the storage unit otherwise would be high relative to $\mathrm{P}_{\mathrm{s}}$.

The results are presented in Figure 8 and Figure 9. The regulation of the storage power, $\mathrm{P}_{\mathrm{s}}$, is damped, and the fast fluctuations in $P_{a}$ are therefore transferred directly to $\mathrm{P}_{\mathrm{x}}$. The constant small power fluctuations come from the fluctuating wind power. The large fast changes in the power come from the large variation of the solar power due to clouds on the sky.

During most of the time shown in Figure 8 and Figure 9 $\mathrm{C}_{\mathrm{d}}$ is positive and the storage unit is producing power to the grid $\left(\mathrm{P}_{\mathrm{s}}>0\right)$. The storage controller also prevents the storage unit from being over- or undercharged (this is not shown).

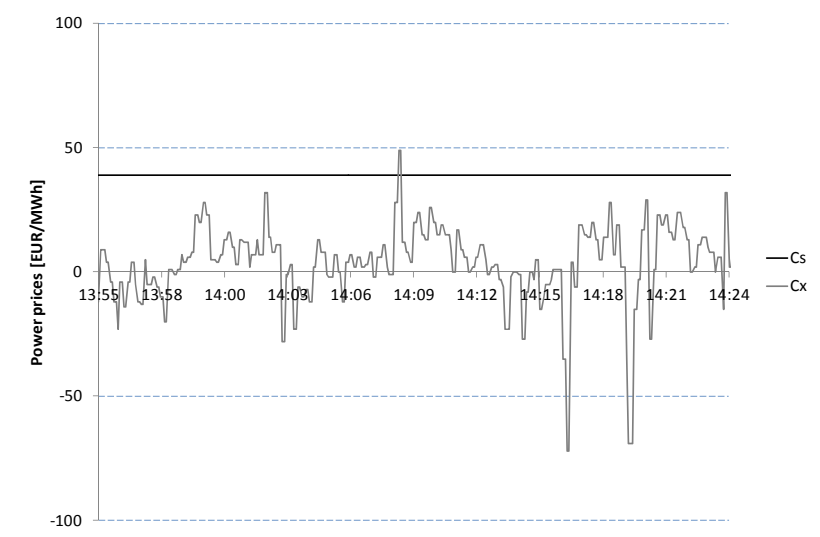

Figure 7: Example of the actual SPOT price, $\mathrm{c}_{\mathrm{s}}$, and the local power price adjustment, $c_{x}$, for a period of $1 / 2$ hour. 
Paper 0267

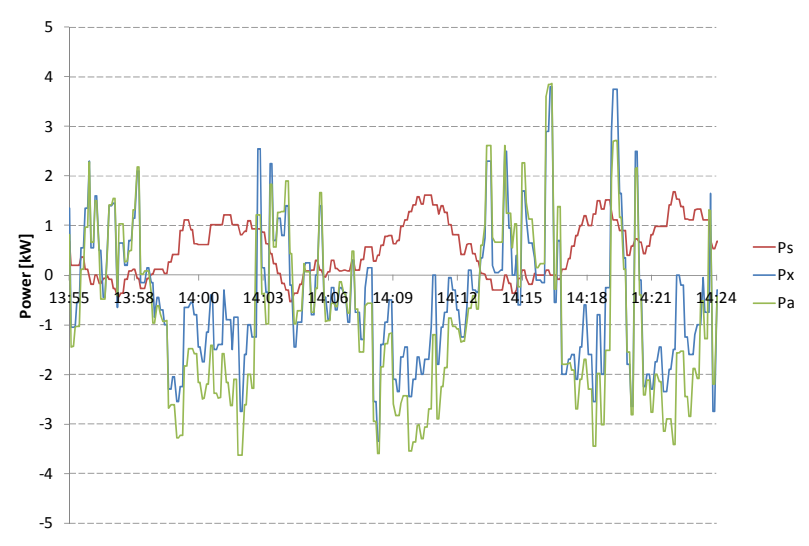

Figure 8: Example of $\mathrm{P}_{\mathrm{a}}, \mathrm{P}_{\mathrm{s}}$ and the resulting $\mathrm{P}_{\mathrm{x}}$ for the same period as Figure 7.

\section{CONCLUSION}

The use of local, dynamic power price - dynamic nodal pricing - for indirect control of distributed active power units (DER units) has been discussed, and the concept has been illustrated in SYSLAB - a small-scale experimental research power system facility at DTU, in the experimental setup including $10 \mathrm{~kW}$ wind power, $7 \mathrm{~kW}$ solar power, $10 \mathrm{~kW}$ office building heating and $15 \mathrm{~kW} /$ $150 \mathrm{kWh}$ electrical storage unit, and connected to the national power grid at simulated limited power capacity of $5 \mathrm{~kW}$.

In the SYSLAB experiment, the local, dynamic power price was generated as a combination of the Nord Pool SPOT price on hourly basis for the given Nord Pool price area (DK2), $c_{s}$, and a local, dynamic price adjustment, $c_{x}$, based on the power exchange, $P_{x}$, between the SYSLAB power system and the national power grid. The power exchange was assumed limited to $5 \mathrm{~kW}$, and only the local storage unit responded to the local price signal. The expected local power price, $\mathrm{c}_{\mathrm{p}}{ }^{\mathrm{exp}}$, was in the illustration the same as the actual SPOT price, $\mathrm{c}_{\mathrm{s}}$.

The storage unit was charging $\left(\mathrm{P}_{\mathrm{s}}<0\right)$, and thereby reducing the power export $\left(\mathrm{P}_{\mathrm{x}}>0\right)$, when the local price difference, $\mathrm{c}_{\mathrm{d}}$, was lower than the price dead band defined for the storage unit, and discharging $\left(\mathrm{P}_{\mathrm{s}}>0\right)$, and thereby reducing the power import $\left(\mathrm{P}_{\mathrm{x}}<0\right)$, when $\mathrm{C}_{\mathrm{d}}$ was higher than the price dead band.

The use of broadcasted local, dynamic power prices is a simple way to activate small-scale distributed active power units (DER units) to provide power system services.

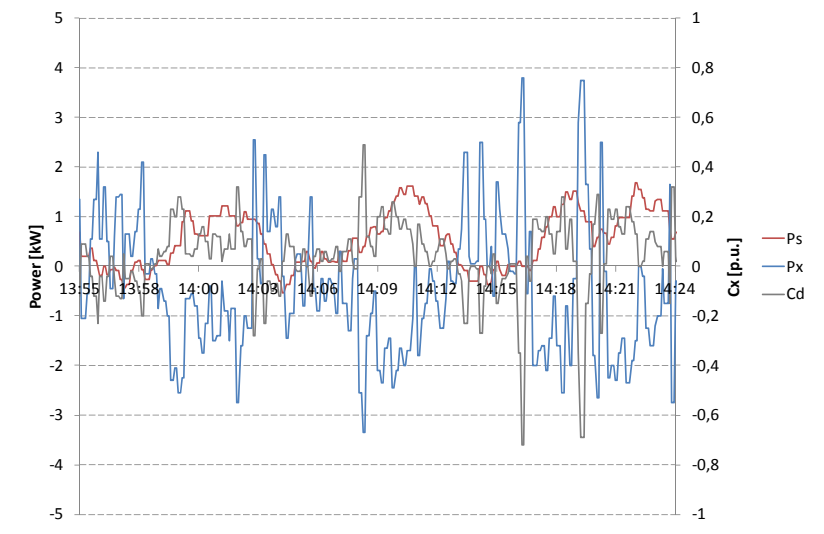

Figure 9: Example of the power exchange, $\mathrm{P}_{\mathrm{x}}$, the local price difference, $c_{d}$, and the storage power, $P_{s}$, for the same period as Figure 7.

\section{REFERENCES}

[1] M. Togeby, 2011, Design of a real time market for regulating power. Report from the FlexPower project. 